\title{
AN INTEGRATED AND INTERACTIVE TOOLBOX FOR THE DESIGN OF COASTAL INFRASTRUCTURE
}

\author{
Freek Scheel, Deltares, Freek.Scheel@deltares.nl \\ Wiebe de Boer, Deltares \& Delft University of Technology, Wiebe.deBoer@deltares.nl \\ Arjen Luijendijk, Deltares \& Delft University of Technology, Arjen.Luijendijk@deltares.nl \\ Ronald Stive, Royal HaskoningDHV, ronald.stive@rhdhv.com \\ Ruud Bouw, Witteveen+Bos, ruud.bouw@witteveenbos.com
}

\begin{abstract}
INTRODUCTION
Coastal engineering design studies often rely on detailed numerical models that involve various monodisciplinary physical processes, complex numerics and large computational demands. As a consequence, these models are particularly useful to address specific questions that arise during project phases focusing on detailed design. In contrast, during early project phases focusing on project feasibility, proof-of-concept and preliminary engineering efforts, these detailed numerical models suffer from their aforementioned characteristics. Now, aspects such as interactivity, flexibility and multidisciplinary assessment are of importance. Simple yet fast tools and empirical relations offer a lot of potential to fill this gap, but are typically not as systematically developed as detailed numerical models. This results in a deficit in consistent integration of disciplines, robustness, interactivity and potential flexibility.
\end{abstract}

\section{MOTIVATION}

In order to support clients and stakeholders in the early design phases of interventions in coastal systems, the Coastal Design and Support (CoDeS) tools framework is developed. This framework combines relatively simple tools and empirical relations to assess various aspects of designs and their impacts. The tools are linked to a consistent and easy-to-use Graphical User Interface (GUI) which is applicable around the globe. The simple nature of the tools allows for:

- Quick first order insights in a range of coastal impacts of human interventions and their designs

- Interactive communication of insights to clients and stakeholders (e.g. in a design session)

- Consistent evaluation of different design aspects simultaneously and for varying design solutions

- Sensitivity and uncertainty analysis for conditions and various design parameters

The usefulness of the CoDeS framework is evident in preliminary design stages, to arrive at promising design solutions and effective communication to clients and stakeholders. In this way, the framework can be used during design sessions, desk assessments and project proposals. Furthermore, the framework is setup in such a way that it can easily be extended with new tools and relations to make it fit for a wide range of applications.

\section{PRESENT STATE}

The CoDes framework is developed in a consortium of Deltares, Royal HaskoningDHV (RHDHV) and Witteveen+Bos (Wi+Bo). The current implementation focusses mainly on port design, with tools for coastline development (incl. impact), wave penetration, flow contraction, port siltation, ecological assessments and breakwater design. The framework facilitates easy import and inspection of relevant environmental data such as tides, waves, coastlines and bathymetry, which can be used throughout the tools. Human interventions can be drawn (designed) on an interactive map and, subsequently, evaluated on various design aspects using the tools. Interaction between the different tools is automatically taken into account. The design can be saved for further analysis in a later stage or used for comparison with other design alternatives.

\section{OPPORTUNITIES}

The development of the CoDeS tools framework provides ample opportunities for future development and collaboration with interested parties:

- Development of toolboxes for other applications such as land reclamations and coastal protection

- Facility for direct comparison of design alternatives

- Functionality for fast sensitivity/uncertainty analysis

- Support for more data formats to import, analyze and export, also from global data sources

- Improve interactive visualization of output for use in presentations, project reports and design sessions

- Initiate further research towards the development of new tools and the relations between them
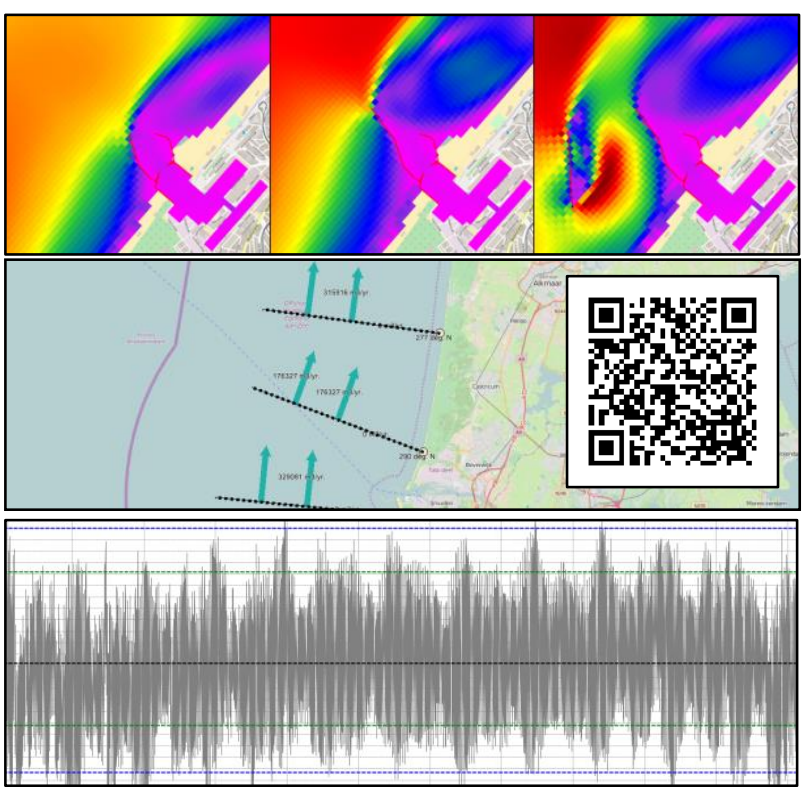

Figure 1 - Examples of CoDes tools applications

\section{ACKNOWLEDGEMENT}

The development of CoDes tools is both funded by the consortium Deltares, RHDHV and $\mathrm{Wi}+\mathrm{Bo}$, as well as subsidized by the Dutch knowledge and innovation consortium for delta technology (TKI).

\section{REFERENCES}

Hoekstra, Scheel, de Boer \& Luijendijk (2013): Development of a harbour design toolbox: opportunities for multidisciplinary rapid assessment in harbour development, Conference proceedings Coasts \& Ports 2013 Sydney, pp. 388-393. 